\title{
Combined use of intracervical foley catheter and vaginal misoprostol for termination of second trimester pregnancy: a three-year observational study
}

\author{
Mohamed $\operatorname{Rezk}^{1 *}$, Mohamed Abo-Elnasr ${ }^{1}$, and Alaa Al-Halaby ${ }^{1}$ \\ ${ }^{1}$ Department of Obstetrics and Gynecology, Faculty of Medicine, Menoufia University, Menoufia, Egypt ${ }^{2}$ \\ ${ }^{2}$ Department of Obstetrics and Gynecology, Faculty of Medicine, Taibah University, Madina, Saudi Arabia
}

\begin{abstract}
Objectives: To assess the effectiveness, safety and acceptability of intracervical foley catheter and vaginal misoprostol versus vaginal misoprostol for termination of second trimester pregnancy.

Methods: This clinical study was conducted on 200 pregnant patients intended for termination of pregnancy between 13-24 gestational weeks for any indication. Enrolled women were equally allocated into two groups:

Group I (Misoprostol group): a standard regimen of moistened misoprostol tablets $(400 \mu \mathrm{g}) 4$ hourly inserted vaginally.

Group II (Combined group): intracervical Foley catheter inserted with a standard regimen of moistened misoprostol tablets (400 $\mu \mathrm{g}) 4$ hourly intravaginally was used.

Procedure efficacy (defined as complete abortion performed on site), safety and acceptability were assessed.

Results: The induction to abortion interval was $8.16 \pm 1.52$ hours in the combined group compared to $12.76 \pm 1.63$ hours in the misoprostol group ( $\mathrm{P}$ value $<0.001$ ) with success rate of $96 \%$ in the combined group and no major complications reported.

Conclusions: Combined use of intracervical foley catheter and vaginal misoprostol is a novel safe, effective and acceptable method for termination of second trimester pregnancy.
\end{abstract}

Synopsis: Combined use of intracervical foley catheter and vaginal misoprostol is a novel safe, effective and acceptable method for termination of second trimester pregnancy.

\section{Introduction}

Second trimester abortions constitute $10-15 \%$ of all induced abortions worldwide but are responsible for two-thirds of all major abortion-related complications [1]. There is a gradual increase in second-trimester abortion because of wide scale introduction of prenatal screening programs detecting women whose pregnancies are complicated by serious fetal abnormalities such as cardiovascular and skeletal malformation [2]. The most efficacious regimen for medical second trimester termination of pregnancy appears to be the use of a combination of mifepristone, followed by misoprostol [3-5]. This regimen has had $97-99 \%$ rate of abortion within 24 hours [3,6]. In countries where mifepristone is not available or affordable, gemeprost or misoprostol alone have been shown to be effective, although a higher total dose is needed and is less effective than the combined regimens [7]. The combination of intravaginal misoprostol and intracervical Foley catheter for second trimester pregnancy termination has been described in two previous studies with conflicting results [8,9]. The aim of this study was to assess the effectiveness, safety and acceptability of intracervical Foley catheter and vaginal misoprostol versus vaginal misoprostol for termination of second trimester pregnancy.

\section{Materials and methods}

This prospective observational single center study was conducted in the Department of Obstetrics and Gynecology at Menoufia University Hospital, Menoufia, Egypt in the period between July 2012 and July 2015.

The study protocol was reviewed and approved by the institutional review board and ethics committee of Menoufia faculty of Medicine and an informed consent was obtained from all participants prior to commencing the study.

Seventy-five patients was required in each group for the study to have $90 \%$ power to detect $10 \%$ difference between two groups regarding

Correspondence to: Mohamed Rezk, MD, Department of Obstetrics and Gynecology, Faculty of Medicine, Menoufia University, Menoufia, Egypt, Tel: 00201006237186,E-mail: m_rezk9207@yahoo.com; Mohamed.abdallah1975@yahoo.com

Keywords: misoprostol, foley catheter, second trimester, pregnancy termination

Received: September 20, 2015; Accepted: October 24, 2015; Published: October 28,2015 
the success rate within 24 hours $(\mathrm{P}=.05,2$-sided $)$. To compensate for possible non-evaluable data, we enrolled over 100 participants in each group.

A total of 209 (1.42\%) pregnant women out of 14682 pregnant women attending the outpatient clinic and emergency room at Menoufia University Hospital, admitted for termination of pregnancy between 13-24 weeks of pregnancy for any indication were enrolled and randomly assigned into two study groups using a computerized random number generator in a sequence of sealed, numbered opaque envelopes, with a 1:1 randomization ratio. Nine patients were dropped out (5 discontinued drug intake and 4 requested removal of the catheter). A total of 200 pregnant women completed the study (Figure 1).

Enrolled patients underwent thorough history taking, clinical examination, obstetric ultrasonography to confirm gestational age, congenital malformation, and placental localization. Patients with previous cesarean or any uterine scar, multiple pregnancies, severe anemia, hypertension, diabetes or with coagulopathy were excluded from the study.

Enrolled patients were divided into two groups:

Group I (Misoprostol group): a standard regimen of moistened misoprostol tablets $(400 \mu \mathrm{g}) 4$ hourly intravaginally was used until abortion.

Group II (Combined group): intracervical Foley catheter inserted, inflated, and placed on traction. Under aseptic conditions, with the patients lying in the lithotomy position, the cervix was assessed and Foley catheter No. 14-16 FrCh was inserted into the endocervical canal, beyond the internal os and the balloon was inflated with $50 \mathrm{ml}$ of normal saline. The catheter was strapped to the thigh and kept in place until it was expelled spontaneously. Patients received a standard regimen of moistened misoprostol tablets $(400 \mu \mathrm{g}) 4$ hourly intravaginally was used until abortion.

The primary outcome of the study was procedure efficacy, defined as complete abortion performed on site within 24 hours with no need for any surgical intervention. Patients in whom effective uterine contractions and cervical dilatation was not obtained within 24 hours with the primary termination method were registered as failures.

Secondary outcomes included safety and acceptability. Safety was assessed by comparing the prevalence of maternal complications. Acceptability included assessment of overall discomfort, likelihood of recommending the abortion method to other women and overall satisfaction rate.

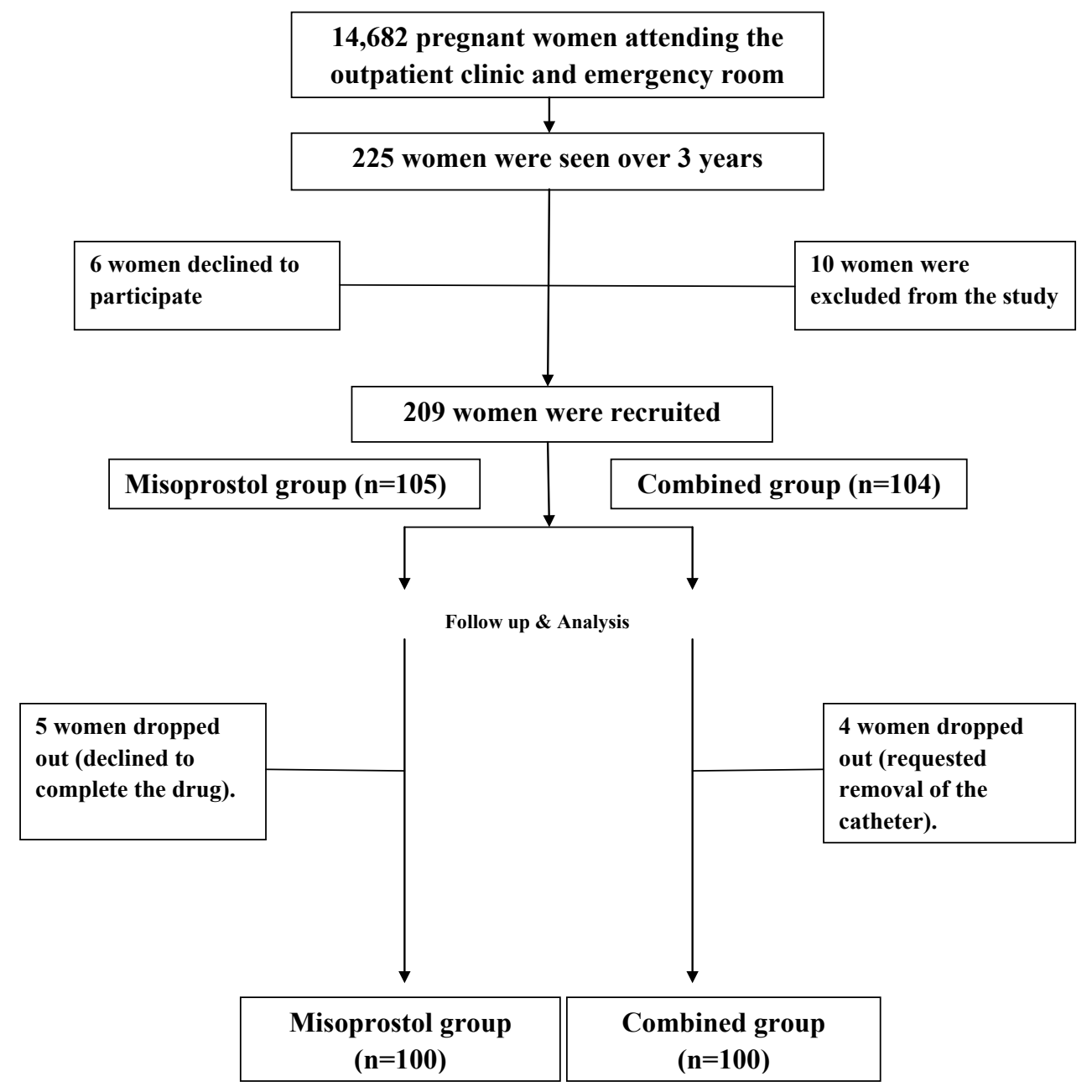

Figure 1. Flow diagram of recruitment and retention of participants in the study. 
The cases were closely monitored for side effects, the onset of contraction, induction to abortion interval. All incomplete abortions were surgically evacuated, the decision to perform surgical evacuation was made on clinical basis, i.e.in cases of heavy bleeding or retained placenta. Routine sonographic evaluation was performed following abortion to confirm the absence of retained products of conception by the obstetrician on duty.

All patients received prophylactic antibiotics, which included a combination of doxycyclin $100 \mathrm{mg}$ and metronidazole $500 \mathrm{mg}$ twice daily for 7 days. Rh antibody was given to all the Rh negative cases at the end of the procedure. All patients were followed up for a period of 4 weeks.

\section{Statistical analysis}

Data were collected, tabulated, statistically analyzed by computer using SPSS version 16(SPSS Inc, Chicago, IL, USA), two types of statistics were done:

\section{1-Descriptive statistics:}

Quantitative data are expressed to measure the central tendency of data and diversion around the mean, mean $(\mathrm{x})$ and standard deviation (SD).

2- Analytic statistics:

Chi-square (x2) and t-test were used to compare two groups.

All these tests were used as tests of significance at

- $P$ value $>0.05$ was considered statistically non significant.

- P value $\leq 0.05$ was considered statistically significant.

-P value $\leq 0.001$ was considered statistically highly significant.

\section{Results}

Table 1 reveals maternal characteristics of the two groups.

Table 2 shows indications of termination of pregnancy\& induction to abortion interval. There was a highly significant difference between the two groups regarding induction to abortion interval $(p<0.001)$ with IAI of $8.16 \pm 1.52$ hours in the combined group in comparison to 12.76 \pm 1.63 hours in the misoprostol group.
Table 3 reveals the maternal complications. There was no significant difference between the two groups regarding the frequency of maternal uterine rupture, cervical lacerations, fever, method failure, nausea \& vomiting, blood transfusion and venous thromboembolism.

Table 4 shows maternal acceptability. There was no significant difference between the two groups regarding the overall discomfort. There was a significant difference between the two groups regarding the likelihood of recommending the abortion method to other women and overall satisfaction rate which was higher in the combined group.

\section{Discussion}

Misoprostol is now widely used for second trimester terminations. However, there is still a need to find out the best route and dose with minimum IAI along with minimal side effects and complications [10].

In low resource settings like our country mifepristone is nonaffordable and non-available. In order to shorten the induction to abortion interval and to minimize the side effects of repeated doses of misoprostol, we used intracervical foley catheter in combination with vaginal misoprostol.

In this study, the induction to abortion interval was $8.16 \pm 1.52$ hours in the combined group which is significantly shorter than using misoprostol alone or when combined with mifepristone that take about $10-15$ hours $[11,12]$.

The rate of surgical evacuation in the present study was $8 \%$ in the misoprostol group which is consistent with the 3-9\% rate described in earlier studies $[3,6]$. The success rate in our study was $96 \%$ in the combined group which is comparable to mifepristone-misprostol combination regimen with lower cost and no additional maternal risks.

A previous single center observational study was conducted in a total of 91 pregnancies. Women who met the termination of pregnancy criteria due to feto-maternal indications between 13 to 26 gestational weeks were included into the study. Study participants received intravaginal misoprostol in combination with Foley catheter $(n=46)$ or intravaginal misoprostol alone $(n=45)$. The authors concluded that combination of intravaginal misoprostol and extraamniotic Foley catheter for second trimester pregnancy termination does not provide additional efficacy with one case experienced uterine rupture in the catheter group [8].

Table 1. Maternal characteristics.

\begin{tabular}{|l|c|c|c|}
\hline & Misoprostol group (n=100) & Combined group (n=100) & t-test \\
\hline Maternal age (years) & $26.50 \pm 3.45$ & $27.49 \pm 3.72$ & 0.03 \\
\hline Parity & $2.60 \pm 0.66$ & $2.57 \pm 0.71$ & $0.307 *$ \\
\hline Gestational age (weeks) & $16.7 \pm 2.99$ & $17.43 \pm 3.19$ & 1.66 \\
\hline Body mass index & $20.02 \pm 1.45$ & $20.28 \pm 1.77$ & $>0.05$ \\
\hline
\end{tabular}

* Mann Whitney test.

Table 2: Indications of termination of pregnancy and induction to abortion interval.

\begin{tabular}{|l|c|c|c|}
\hline & Misoprostol group (n=100) & Combined group (n=100) & t-test \\
\hline -IUFD & 60 & 58 & $1.99 *$ \\
-Congenital anomalies & 27 & 31 & $>0.05$ \\
\hline -PPROM & 13 & 11 & \\
\hline IAI & $12.76 \pm 1.63$ & $8.16 \pm 1.52$ & 14.223 \\
\hline
\end{tabular}

*Chi-square test, IUFD=Intrauterine Fetal Demise, PPROM=Preterm Premature Rupture of Membranes, IAI: Induction to abortion interval. 
Table 3. Maternal complications.

\begin{tabular}{|c|c|c|c|c|c|}
\hline & Misoprostol group $(n=100)$ & Combined group $(n=100)$ & Chi-square test & P-value & Odd's ratio(CI 95\%) \\
\hline Uterine rupture & 0 & 0 & - & - & - \\
\hline Cervical lacerations & 4 & 6 & 0.421 & $>0.05$ & $2(-5.03 ; 9.03)$ \\
\hline Fever & 7 & 13 & 2.00 & $>0.05$ & $6(-3.2 ; 15.2)$ \\
\hline Method failure & 8 & 4 & 1.418 & $>0.05$ & $4(-3.5 ; 11.5)$ \\
\hline Nausea \& vomiting & 6 & 8 & 0.307 & $>0.05$ & $2(-6 ; 10)$ \\
\hline Blood transfusion & 5 & 9 & 1.229 & $>0.05$ & $4(-4.05 ; 12)$ \\
\hline Venous Thromboembolism & 0 & 0 & - & - & - \\
\hline
\end{tabular}

CI $95 \%=$ Confidence interval $95 \%$.

Table 4. The acceptability of methods of termination of pregnancy.

\begin{tabular}{|c|c|c|c|c|}
\hline & Misoprostol group $(n=100)$ & Combined group $(n=100)$ & Chi square & P-value \\
\hline $\begin{array}{l}\text { Overall discomfort with abortion: } \\
\text {-Moderate/High/Extreme } \\
\text {-None or slight }\end{array}$ & $\begin{array}{l}14 \\
86\end{array}$ & $\begin{array}{l}10 \\
90\end{array}$ & 0.757 & $>0.05$ \\
\hline $\begin{array}{l}\text { Overall Satisfaction with abortion: } \\
\text {-Very or somewhat satisfied } \\
\text {-Neutral or somewhat not satisfied }\end{array}$ & $\begin{array}{l}82 \\
18\end{array}$ & $\begin{array}{c}94 \\
6\end{array}$ & 2.39 & $<0.05$ \\
\hline $\begin{array}{l}\text { Would recommend the abortion method to other women: } \\
\text {-Highly or somewhat agree } \\
\text {-Neutral or somewhat disagree }\end{array}$ & $\begin{array}{l}80 \\
20\end{array}$ & $\begin{array}{c}92 \\
8\end{array}$ & 2.24 & $<0.05$ \\
\hline
\end{tabular}

More recently, we conducted comparative study including 90 pregnant women intended for termination of pregnancy between 13 and 24 gestational weeks for any indication. Enrolled women were equally allocated into three groups the first received vaginal misoprostol $(n=30)$, the second received intracervical Foley catheter alone $(n=30)$ and the third received both $(\mathrm{n}=30)$. The induction to abortion interval was $7.5 \pm 1.25 \mathrm{~h}$ in the combined group, compared to $11.76 \pm 1.63 \mathrm{~h}$ in the misoprostol group and $19.76 \pm 1.52 \mathrm{~h}$ in the catheter group $(\mathrm{p}$ value $<0.001$ ) with a success rate of $100 \%$ and no major complications reported [9].

A recent randomized clinical trial to evaluate the efficacy of two routes of administration of misoprostol (sublingual and vaginal) for medical termination of second trimester pregnancies over 48 hours. The success rate was $61.2 \%(\mathrm{n}=41)$ in the vaginal group versus $70.1 \%$ $(n=47)$ in the sublingual group $(\mathrm{p}=0.3)$. Twenty-six patients $(38.8 \%)$ in the vaginal group underwent $\mathrm{D} \& \mathrm{C}$ due to retained tissue, compared with 20 patients (29.8\%) in the sublingual group [13].

The use of intracervical Foley catheter may act in addition to its mechanical effect by increasing the release of prostaglandin and/or oxytocin release secondary to localized inflammation [14].

In our study, the frequency of fever was higher in the combined group but still insignificant in comparison to misoprostol group as the use of intracervical Foley catheter is associated with a significant increase in intracervical pathogenic organisms despite undertaking routine aseptic measures as proved in a previous study [15].

Inability to conduct a double blind multi-center study and to include women with previous uterine scar were the main limitation of our study.

From the results obtained in this observational study, the combined use of intracervical foley catheter and vaginal misoprostol is a novel safe, effective and acceptable method for termination of second trimester pregnancy which is comparable to mifepristone-misprostol combination regimen with lower cost and no additional maternal risks.

\section{Acknowledgements}

The authors would like to acknowledge the contribution of the residents and nursing staff of the delivery ward of Menoufia university Hospital.

\section{Disclosure}

We certify that no actual or potential conflicts of interest in relation to this article exist.

\section{References}

1. Drey EA, Foster DG, Jackson RA, Lee SJ, Cardenas LH, et al. (2006) Risk factors associated with presenting for abortion in the second trimester. Obstet Gynecol 107: 128-135. [Crossref]

2. Boyd PA, Tondi F, Hicks NR, Chamberlain PF (2004) Autopsy after termination of pregnancy for fetal anomaly: retrospective cohort study. BMJ 328: 137. [Crossref]

3. Hamoda H, Ashok PW, Flett GM, Templeton A (2005) A randomized trial of mifepristone in combination with misoprostol administered sublingually or vaginally for medical abortion at 13-20 weeks gestation. Hum Reprod 20: 2348-2354. [Crossref]

4. Gemzell-Danielsson K, Lalitkumar S (2008) Second trimester medical abortion with mifepristone-misoprostol and misoprostol alone: a review of methods and management. Reprod Health Matters 16: 162-172. [Crossref]

5. Lohr PA, Hayes JL, Gemzell-Danielsson K (2008) Surgical versus medical methods for second trimester induced abortion. Cochrane Database Syst Rev CD006714. [Crossref]

6. Ashok PW, Templeton A, Wagaarachchi PT, Flett GM (2004) Midtrimester medical termination of pregnancy: a review of 1002 consecutive cases. Contraception 69: 5158. [Crossref]

7. Ngai SW, Tang OS, Ho PC (2000) Randomized comparison of vaginal (200 microg every $3 \mathrm{~h}$ ) and oral (400 microg every $3 \mathrm{~h}$ ) misoprostol when combined with mifepristone in termination of second trimester pregnancy. Human Reproduction 15 : 2205-2208.

8. Toptas T, Mendilcioglu I, Simsek M, Taskin O (2014) Intravaginal misoprostol alone 
Rezk M (2015) Combined use of intracervical foley catheter and vaginal misoprostol for termination of second trimester pregnancy: a three-year observational study

versus intravaginal misoprostol and extraamniotic Foley catheter for second trimester pregnancy termination: an observational study. Ginekol Pol 85: 577-581. [Crossref]

9. Rezk MA, Sanad Z, Dawood R, Emarh M, Masood A(2015) Comparison of intravaginal misoprostol and intracervical Foley catheter alone or in combination for termination of second trimester pregnancy. J Matern Fetal Neonatal Med 28: 93-96. [Crossref]

10. Kunwar S, Saha PK, Goel P, Huria A, Tandon R, et al. (2010) Second trimester pregnancy termination with $400 \mu \mathrm{g}$ vaginal misoprostol: efficacy and safety. Biosci Trends 4: 351-354. [Crossref]

11. Herabutya Y, Chanrachakul B, Punyavachira P (2000) Vaginal misoprostol in termination of second trimester pregnancy. Journal of Obstetrics and Gynaecology Research 26: 121-125.
12. Herabutya Y, Chanrachakul B, Punyavachira P (2001) Second trimester pregnancy termination: a comparison of 600 and 800 micrograms of intravaginal misoprostol. $J$ Obstet Gynaecol Res 27: 125-128. [Crossref]

13. Tanha FD, Golgachi T, Niroomand N, Ghajarzadeh M, Nasr R (2013) Sublingual versu vaginal misoprostol for second trimester termination: a randomized clinical trial. Arch Gynecol Obstet 287: 65-69. [Crossref]

14. Jozwiak M, Bloemenkamp KW, Kelly AJ, Mol BW, Irion O, et al. (2012) Mechanical methods for induction of labour. Cochrane Database Syst Rev 3: CD001233. [Crossref]

15. Siddiqui S, Zuberi NF, Zafar A, Qureshi RN (2003) Increased risk of cervical canal infections with intracervical Foley catheter. J Coll Physicians Surg Pak13: 146-149. [Crossref]

Copyright: $(02015$ Rezk M. This is an open-access article distributed under the terms of the Creative Commons Attribution License, which permits unrestricted use, distribution, and reproduction in any medium, provided the original author and source are credited. 